\title{
Evaluation of Maize Inbreds for Maize stripe virus and Maize mosaic virus Resistance: Disease Progress in Relation to Time and the Cumulative Number of Planthoppers
}

\author{
J. Dintinger, N. Boissot, F. Chiroleu, P. Hamon, and B. Reynaud
}

First, third, and fifth authors: CIRAD UMR 'Peuplements Végétaux et Bioagresseurs en Milieu Tropical' (PVBMT), CIRAD/Université de la Réunion, 7 chemin de l'IRAT, 97410 Saint-Pierre, La Réunion, France; second author: INRA-UGAFL, Domaine Saint-Maurice, BP94, 84143 Montfavet Cedex, France; and fourth author: Centre Universitaire de Formation et de Recherche, Nîmes, France. Accepted for publication 6 January 2005.

\begin{abstract}
Dintinger, J., Boissot, N., Chiroleu, F., Hamon, P., and Reynaud, B. 2005. Evaluation of maize inbreds for Maize stripe virus and Maize mosaic virus resistance: Disease progress in relation to time and the cumulative number of planthoppers. Phytopathology 95:600-607.

Five tropical maize lines were tested and compared with the susceptible control line B73 for resistance to Maize stripe virus (MStV) and Maize mosaic virus (MMV), both propagatively transmitted by the planthopper Peregrinus maidis (Homoptera: Delphacidae). Resistance to each virus was evaluated separately by artificial inoculations with planthoppers viruliferous for either one virus or the other. Disease incidence and symptom severity progression were quantified in relation to time and the cumulative number of planthoppers. Line Hi40 was found to be susceptible to MStV and highly resistant to MMV. Generally, no MMV symptoms developed on Hi40, even under intense inoculation pres-

incidence. Nevertheless, this resistance to MStV was the highest ever reported and held up, even when challenged by large numbers of planthoppers. The percentage of infected plants in line Rev81 never exceeded 30 to $40 \%$ in our experiments. Moderate levels of resistance to $\mathrm{MStV}$, and to a lesser extent MMV, were found in lines 37-2, A211, and Mp705. However, resistance in these lines was completely overcome using a large number of insects transmitting either of the two viruses. These results suggest that different types of resistance to MMV and MStV are available in maize lines from Caribbean and Mascarene germ plasm. The expression of virus-specific resistance identified in Hi40 and Rev81 lines was not affected by intense inoculation pressure. In contrast, the moderate resistance in 37-2, A211, and Mp705 was partially effective against both viruses but not at high inoculation pressure. These different types of resistance, when present in the same genotype, could provide protection against both viruses.
\end{abstract} sure by a large number of viruliferous planthoppers. Line Rev81 showed a partial but strong resistance to $\mathrm{MStV}$, which mainly reduced disease
Additional keywords: maize resistance.
Maize stripe virus (MStV) and Maize mosaic virus (MMV), members of the genera Tenuivirus and Nucleorhabdovirus, cause distinct and severe diseases of maize (Zea mays L.) in tropical and subtropical areas of Africa (28), the Americas (15,23), and Australia (11). Both viruses are transmitted by the planthopper Peregrinus maidis (Ashmead) (Homoptera: Delphacidae) and have overlapping geographical distributions. Both viruses propagate in the insect vector $(10,21,22)$, but MStV also can be transovarially passed (1). Maize is the favored host plant of the P. maidis-MStV-MMV complex, although several Sorghum spp. and some wild grasses of related genera also can be infected $(2,19)$. In Réunion Island, the two diseases are severe, often occur simultaneously, and are coincident with their widely distributed vector. Maize fields infested by populations of $P$. maidis viruliferous for both viruses are common, especially in the irrigated lowlands, but also in mid-elevation areas where the vector can survive year-round $(8,18,26)$.

Because of environmental considerations and the difficulty in controlling vectors with insecticides, use of varietal resistance is the most effective and convenient strategy for minimizing losses caused by viral diseases. In many areas, the high likelihood of natural mixed infections by MStV and MMV is a major argument for adopting a strategy of breeding maize resistant to both dis-

Corresponding author: J. Dintinger; E-mail address: jacques.dintinger@cirad.fr

DOI: 10.1094/PHYTO-95-0600

(C) 2005 The American Phytopathological Society eases. Therefore, studies were initiated to characterize different sources of resistance in maize that could be used against MStV, MMV, and the vector $P$. maidis. Resistance to MMV was first identified and mapped as a single locus in lines derived from Caribbean germ plasm $(20,25)$. In other respects, population 'Revolution' from Réunion Island has been known as a source of resistance to MStV (9). Maize germ plasm from Réunion was shown to be an excellent source of resistance to several viruses $(7,12)$, and lines resistant to MStV and MMV were extracted from local populations. The objective of this study was to evaluate resistance to MStV and MMV in some tropical maize lines. To do this, we quantified and compared MStV and MMV incidence and severity in field plots after vector inoculation with either MStV or MMV.

\section{MATERIALS AND METHODS}

Plant material. Six maize inbred lines were tested in field experiments. The line Hi40, selected from the cross between Antigua group 2 and Hi25 (3), was the most resistant genotype to MMV under conditions in Réunion Island. The maize line highly resistant to MStV, Rev81, was selected from population 'Révolution' in trials with artificial inoculation of virus (unpublished data). The Maize streak virus-resistant line A211, selected from population IRAT297 (27), had an intermediate level of resistance to MMV under artificial inoculation field trials (4). Another line from IRAT297, 37-2, was selected for resistance to transmission of MMV (4). The Caribbean line Mp705, selected from MP SWCB-4, is resistant to two Lepidoptera (29), and preliminary 
observations indicated resistance to transmission of MMV (4). The temperate B73 line, from the Iowa Stiff-Stalk Synthetic, was used as a highly susceptible control.

Artificial inoculations and disease assessment. Disease incidence and severity were assessed after inoculation with massreared planthoppers viruliferous for either MMV or MStV. These planthoppers were produced by using maize varieties, susceptible to one virus and highly resistant to the other, to avoid cross-contamination. For MStV, we used a three way hybrid, $(\mathrm{Hi} 40 \times$ Hi31)/CVR12, susceptible to MStV and highly resistant to MMV; CVR12 being a resistant line to MMV selected in population IRAT297 from Réunion. For MMV, we used a single hybrid, Rev81 × Rev156, susceptible to MMV and resistant to MStV; Rev81 and Rev156 being resistant lines to MStV selected from population 'Révolution' (unpublished data). Planthoppers were mass-reared on virus-infected source plants, such that they were exposed to the virus from larva stage one to adult stage. Larvae at stage four and adults were used for transmission. The MMV and MStV isolates came from the CIRAD Experimental Station of Ligne Paradis, Saint-Pierre, Réunion Island, and have been maintained by successive cycles of mass rearing on the varieties described previously.

Seeds of the inbred lines tested were germinated in a greenhouse and thinned to one seedling per pot. Seedlings at the twoleaf stage were placed into infestation cages ( 1.0 by 1.0 by $1.5 \mathrm{~m}$ ) each containing 6,000 to 8,000 insects mass-reared on virus-infected plants. In each cage within each trial, three inoculation-access period (IAP) durations were used by exposing the seedlings to viruliferous planthoppers for 6,24 , or $96 \mathrm{~h}$. One single cage corresponded to one block of the split plot design (described below). Seedlings were removed from the cages after 6,24 , or $96 \mathrm{~h}$ and sprayed with an insecticide before being transplanted within screenhouses (one screenhouse for each block of the split plot design). In the screenhouses, plants were sprayed with a systemic insecticide weekly. Symptoms were evaluated on the last fully expanded leaf of each plant on a 1 (no symptom) to 10 (dead plant) scale established for each virus. These scales were based on the proportion of chlorotic area of the leaf, with a score of 2 for a chlorotic area $<10 \%, 3$ for chlorotic area between 10 and $20 \%$, and 9 corresponding to maximal development of leaf chlorosis (between 70 and $80 \%$ ) and very severe stunting. The ratings were recorded weekly on individual plants for up to 42 days postinoculation (dpi).

In each cage and for each IAP, we estimated the mean number of insects feeding per plant by counting a total of 60 plants (10 plants per line) after 6-, 24-, and 96-h IAP before transplanting the plants in the screenhouses. Since we did not determine if insects fed on the plants, we simply assumed that each insect still alive when counted had fed on the plant. At the same time, transmission efficiency, defined as proportion of inoculative insects, was determined on a sample of 100 individuals collected from the different cages and representing the whole population of insects for a given experiment. Single planthoppers were each confined in small PVC tube cages containing one susceptible maize seedling at the two-leaf stage and maintained in a growth chamber $\left(25^{\circ} \mathrm{C}, 16\right.$-h light/8-h dark photoperiod). After a 72 -h IAP, plants were sprayed with an insecticide and placed in a screenhouse. The occurrence of chlorotic stripe symptoms on the leaves was recorded 28 days later.

Experimental field design. Five trials were conducted with each virus at the CIRAD Experimental Station of Ligne Paradis, Saint-Pierre, Réunion Island (lowland tropical environment, elevation $140 \mathrm{~m}, 20^{\circ} \mathrm{S}$ ) during different maize cropping seasons over the years 1998 to 2000 . For each trial, a split plot design was laid out with three main plots per block and six subplots within a main plot. Main plots corresponded to three IAP durations in the cages. Subplots corresponded to six inbred lines tested. The number of blocks (cages) varied between three and eight per trial.
Within each trial, one block was a free-standing screenhouse made up of insect-proof netting (mesh size $07 \times 04 \mathrm{~mm}$ ). Inside the screenhouse, each subplot consisted of one single row of 24 plants.

Variable description. The variables, calculated on a subplot basis, were disease incidence ( inc $_{u}$ ), defined as the percentage of plants exhibiting symptoms at the $u$ th dpi, and disease severity $\left(\operatorname{sev}_{u}\right)$, defined as the mean disease score of the plants exhibiting symptoms at the $u$ th dpi. To integrate these variables over time, we calculated the area under the disease progress curve (AUDPC) (13), called inc ${ }_{a}$ for the disease incidence and $\operatorname{sev}_{a}$ for the disease severity.

$$
\operatorname{inc}_{a}=\sum_{i=1}^{n-1}\left\{\left[\left(\mathrm{inc}_{i}+\operatorname{inc}_{i+1}\right) / 2\right]\left(t_{i+1}-t_{i}\right)\right\} /\left(t_{n}-t_{1}\right)
$$

in which inc $_{i}$ was the percentage of plants exhibiting symptoms at the $i$ th rating date and

$$
\operatorname{sev}_{a}=\sum_{i=1}^{n-1}\left\{\left[\left(\operatorname{sev}_{i}+\operatorname{sev}_{i+1}\right) / 2\right]\left(t_{i+1}-t_{i}\right)\right\} /\left(t_{n}-t_{1}\right)
$$

in which $\operatorname{sev}_{i}$ was the mean disease score of the plants exhibiting symptoms at the $i$ th rating date, $t_{i}$ was the time postinoculation at the $i$ th observation, and $n$ was the number of dates at which disease was recorded. The AUDPCs were standardized by dividing the value by the total time duration $\left(t_{n}-t_{1}\right)$ of the disease progress study which varied from 42 to $56 \mathrm{dpi}$, depending on the trial. The first interval of time was between 0 and $7 \mathrm{dpi}$.

For estimating the disease progress in relation to inoculation pressure, we used the cumulative number of planthoppers cniph, according to the formula

$$
c n i p h_{i j k}=r_{i} \sum_{n=1}^{k} \bar{x}_{i j n} \cdot t_{n}
$$

where cniph $_{i j k}$ is the cumulative number of inoculative planthoppers $\times$ hours at the $k$ th IAP $(k=1$ for $6 \mathrm{~h}, 2$ for $24 \mathrm{~h}$, and 3 for $96 \mathrm{~h}$ ), in the $j$ th cage of the $i$ th trial; $\bar{x}_{i j n}$, the mean number of planthoppers per plant (visually estimated) in the $j$ th cage of the $i$ th trial during $t_{n}$ hours; $t_{n}$, the number of hours corresponding to first IAP $(6 \mathrm{~h}, n=1)$, the difference between second and first IAP (18 h, $n=2$ ), or the difference between third and second IAP (72 $\mathrm{h}, n=3$ ); and $r_{i}$, the proportion of inoculative planthoppers overall estimated on the $i$ th trial.

Statistics. The disease incidence and severity of each plot were calculated for each rating date. Within each trial and for each IAP, nonlinear regression analyses of nontransformed averaged data from each line were performed for the monomolecular, logistic, and Gompertz models (SAS NLIN procedure using the DUD option, version 6.12; SAS Institute, Cary, NC). On the basis of adjusted $R^{2}$, the Gompertz model (6) was found to be the most appropriate to quantify temporal increase of MStV as well as of MMV: $Y=A \cdot \exp \{-\exp [-B(X-C)]\}$, where $Y=$ percentage (incidence) or mean disease score (severity) of plants exhibiting symptoms; $X=$ number of dpi; and $A, B$, and $C=$ the parameters to be estimated. In the curve, $A=$ maximum disease incidence or severity (upper asymptote), $B=$ rate of disease progress (slope parameter), and $C=$ point of inflection (time needed to achieve $37 \%$ of the maximum disease incidence or severity). A separate curve was fitted for each line in each IAP within each trial. The parameters of the fitted Gompertz curves were then analyzed for disease incidence and severity. The genotype effect on the curve parameters $A, B$, and $C$ was tested in an analysis of variance (ANOVA) on multitrial basis, taking the IAP, the trial, and the genotype-trial interaction into account. Ryan-Einot-Gabriel-Welsh multiple range tests (REGW $Q$ test) $(\alpha=0.05)$ were used for testing pairwise differences between means.

The effect of genotype on the disease progress in relation with the cniph was determined for both incidence and severity of each virus. ANOVA was performed on arcsine-transformed data in 
each trial individually, for each IAP separately, taking the cage effect into account. The variables analyzed were inc ${ }_{a}, \operatorname{sev}_{a}$, inc $_{42}$, and $\operatorname{sev}_{42}$. Means were separated by the REGW $Q$ test $(\alpha=0.05)$.

\section{RESULTS}

Artificial inoculations and environmental conditions. Artificial inoculations were successful for MStV and MMV. On the susceptible check B73, $100 \%$ of the plants had a symptom severity greater than 8 or were dead at 28 days following a 24- or 96-h IAP in each MStV trial, and following a 96-h IAP in each MMV trial, except in MMV trial 2000-A. Transmission efficiency of the virus was estimated from 30 to $60 \%$ for MStV compared with 12 to $24 \%$ for MMV, depending on the trial. Therefore, the cniphestimated values were on average about three times higher in the MStV trials than in the MMV trials (Table 1). The hot and wet season (January to April) resulted in the poorest production of inoculative planthoppers for both viruses. For both viruses, most infected plants developed first symptoms 7 to $21 \mathrm{dpi}$, depending on the season and maize genotype. B73 plants always showed the earliest symptoms and the highest rate of mortality.

MStV disease progress curves. All the Gompertz disease progress curves fitted the experimental data for incidence as well as for severity, resulting in a total of 90 modelized curves for each variable. Adjusted $R^{2}$ values ranged from 0.94 to 1.00 for incidence and from 0.95 to 1.00 for severity. The mean values of the maximum incidence and severity $(A)$, of the rate of progress $(B)$, and of the inflexion point $(C)$ were obtained from an ANOVA of the Gompertz parameters over the five trials (Table 2). Then, these parameters were used to quantify MStV progression and to make comparisons among the six genotypes (Fig. 1A and B). For both incidence and severity, when $A$ and $B$ decreased, $C$ increased, according to genotype.

The $F$ test for genotype effect was significant at $P=0.0001$ for $A$ and $C$ and at $P=0.0002$ for $B$, indicating that the lines differed for $\mathrm{MStV}$ incidence with regard to each Gompertz parameter (Table 2, incidence). We also observed a significant effect of the trial $(P=0.0001$ for $A$ and $C$ and $P=0.0034$ for $B)$, of the IAP ( $P=0.0001$ for $A$ and $P=0.0045$ for $C$ ), and of the interaction genotype-trial $(P=0.0001$ for $A$ and $P=0.0184$ for $C$ ). The maximum percentage of diseased plants $(A)$ ranged from $17 \%$, for the most resistant line Rev81, to $95 \%$, for B73, the susceptible

TABLE 1. Estimation of the cumulative number of inoculative planthoppers $\times$ hours (cniph) in Maize stripe virus (MStV) and Maize mosaic virus (MMV) trials

\begin{tabular}{lcccc}
\hline & \multicolumn{3}{c}{ IAP $(\mathrm{h})^{\mathrm{z}}$} & \\
\cline { 2 - 4 } Year-season $^{\mathrm{y}}$ & 6 & 24 & 96 & Trial mean \\
\hline MStV 1998-C & $365(36)$ & $1,000(168)$ & $4,609(640)$ & $1,991(688)$ \\
MStV 1999-B & $72(5.9)$ & $338(22)$ & $2,220(166)$ & $877(206)$ \\
MStV 1999-C & $53(3.7)$ & $203(11)$ & $1,146(121)$ & $467(108)$ \\
MStV 2000-A & $16(2.4)$ & $68(4.2)$ & $366(23)$ & $150(42)$ \\
MStV 2000-B & $98(14)$ & $229(31)$ & $656(121)$ & $328(66)$ \\
IAP mean & $92(18)$ & $299(48)$ & $1,522(234)$ & $\ldots$ \\
General mean & $\ldots$ & $\ldots$ & $\ldots$ & $638(103)$ \\
MMV 1998-C & $26(3.4)$ & $172(28)$ & $968(88)$ & $389(104)$ \\
MMV 1999-B & $30(2.4)$ & $148(19)$ & $639(84)$ & $272(69)$ \\
MMV 1999-C & $15(0.2)$ & $108(6.3)$ & $541(32)$ & $221(82)$ \\
MMV 2000-A & $40(4.0)$ & $120(14)$ & $199(16)$ & $119(16)$ \\
MMV 2000-B & $59(9.1)$ & $119(6.8)$ & $335(46)$ & $171(38)$ \\
IAP mean & $35(3.1)$ & $138(9.6)$ & $526(62)$ & $\ldots$ \\
General mean & $\ldots$ & $\ldots$ & $\ldots$ & $235(32)$ \\
\hline
\end{tabular}

y A, B, and C correspond to hot and wet season (January to April), fresh and semi-dry season (May to August), and hot and dry season (September to December), respectively.

${ }^{\mathrm{z}}$ IAP, inoculation access period (total time, in hours, during which the plantlets were in the cages with insects). Numbers represent means over all cages (standard error). check. Rev81 took twice as long as B73 to reach $37 \%$ of the maximum incidence. Lines Mp705, A211, and 37-2 showed intermediate levels of resistance, whereas Hi40 was nearly as susceptible as B73.

The $F$ test for genotype effect was significant at $P=0.0001$ for $A, B$, and $C$, indicating that the lines differed for MStV severity with regard to each Gompertz parameter (Table 2, severity). We also found a significant effect of the trial $(P=0.0001$ for $A$ and $C$ and $P=0.0032$ for $B)$, of the $\operatorname{IAP}(P=0.01$ for $A$ and $P=0.0001$ for $C$ ), and of the interaction genotype-trial $(P=0.0001$ for $A$ and $C)$. Rev81 was the only line showing a maximum severity $(A)$ significantly lower than for control B73, with symptom development delayed.

MMV disease progress curves. Because of the near absence of MMV symptoms on line Hi40, only seven Gompertz disease progress curves were obtained from this genotype for either incidence or severity, resulting in a total of 82 modelized curves for each variable. Adjusted $R^{2}$ values ranged from 0.90 to 1.00 for incidence and from 0.94 to 1.00 for severity. The mean values of the maximum incidence and severity $(A)$, of the rate of progress $(B)$, and of the inflection point $(C)$ were obtained from an ANOVA of the Gompertz parameters over the five trials (Table 3). Then, these parameters were used to quantify MMV progression and to make comparisons among the six genotypes (Fig. 1C and D). For incidence, when $A$ and $B$ decreased, $C$ increased, according to the genotype. For severity, this relation only was found when comparing Hi40 with the other genotypes. In our experiments, line Hi40 showed very few plants $(<1.4 \%)$ expressing MMV mild symptoms, the severity of which was $<3$ on the rating scale. Thus, this resistant line strongly differed from the others, and the ANOVAs for both variables were performed without inclusion of Hi40 in an effort to describe, more accurately, differences between the partially resistant lines.

The $F$ test for genotype effect was significant at $P=0.0001$ for $A, B$, and $C$, indicating that the lines differed for MMV incidence with regard to each Gompertz parameter (Table 3, incidence). We also observed a significant effect of the trial $(P=0.0001$ for $A, B$, and $C)$ and of the IAP $(P=0.0001$ for $A$ and $C$ and $P=0.0008$ for $B)$. The maximum percentage of diseased plants $(A)$ ranged from $45 \%$ for the partially resistant line $37-2$ to $77 \%$ for B73, the susceptible control. Line 37-2 took twice as long as B73 to reach $37 \%$ of the maximum incidence. Lines Rev81, A211, and Mp705 were less susceptible than B73 and showed no significant differences between them.

TABLE 2. Parameter estimates of Gompertz curves fitted to the Maize stripe virus incidence and severity for six inbred lines

\begin{tabular}{llclc}
\hline & & \multicolumn{3}{c}{ Gompertz curves parameters $^{\mathrm{z}}$} \\
\cline { 3 - 5 } & Line & $A$ & \multicolumn{1}{c}{$B$} & $C$ \\
\hline Incidence & $37-2$ & $52.0(7.1) \mathrm{c}$ & $0.293(0.028) \mathrm{bc}$ & $10.26(0.76) \mathrm{b}$ \\
& A211 & $46.6(7.8) \mathrm{c}$ & $0.291(0.028) \mathrm{bc}$ & $10.86(1.00) \mathrm{ab}$ \\
& B73 & $95.4(2.7) \mathrm{a}$ & $0.468(0.054) \mathrm{a}$ & $7.21(0.47) \mathrm{c}$ \\
& Hi40 & $86.4(4.4) \mathrm{b}$ & $0.385(0.050) \mathrm{ab}$ & $9.57(0.97) \mathrm{b}$ \\
& Mp705 & $36.3(7.0) \mathrm{d}$ & $0.296(0.022) \mathrm{bc}$ & $10.98(1.09) \mathrm{ab}$ \\
& Rev81 & $16.6(3.0) \mathrm{e}$ & $0.225(0.020) \mathrm{c}$ & $12.90(0.75) \mathrm{a}$ \\
Severity & 37-2 & $8.78(0.30) \mathrm{a}$ & $0.112(0.009) \mathrm{bc}$ & $19.91(1.72) \mathrm{b}$ \\
& A211 & $8.32(0.53) \mathrm{a}$ & $0.113(0.011) \mathrm{bc}$ & $21.52(1.54) \mathrm{b}$ \\
& B73 & $8.86(0.14) \mathrm{a}$ & $0.208(0.026) \mathrm{a}$ & $12.74(1.17) \mathrm{d}$ \\
& Hi40 & $8.85(0.17) \mathrm{a}$ & $0.151(0.016) \mathrm{b}$ & $16.80(1.46) \mathrm{c}$ \\
& Mp705 & $8.09(0.67) \mathrm{a}$ & $0.113(0.006) \mathrm{bc}$ & $19.66(1.50) \mathrm{b}$ \\
& Rev81 & $6.90(0.76) \mathrm{b}$ & $0.079(0.010) \mathrm{c}$ & $27.28(2.30) \mathrm{a}$ \\
\hline
\end{tabular}

${ }^{\mathrm{z}}$ Numbers indicate the maximum percentage of plants presenting visible symptoms, for incidence, and the maximum mean score of plants presenting symptoms, for severity. Results are the means of five experiments (standard error). $A=$ upper asymptote, $B=$ slope parameter, and $C=$ point of inflexion. Values followed by the same letters are not significantly different at the 0.05 level according to Ryan-Einot-Gabriel-Welsh multiple range tests (REGW $Q$ test). 
The $F$ test for genotype effect was significant at $P=0.0001$ for $B$ and $C$, indicating that the lines differed for MMV severity with regard to rate of disease progress and time to reach the point of inflection (Table 3, severity). We also observed a significant effect of the trial $(P=0.0001$ for $A, B$, and $C)$, of IAP $(P=0.0016$ for $B$ and $P=0.0001$ for $C)$, and of the interaction genotype-trial $(P=$ 0.0001 for $C$ ). When compared with B73, symptom development on the resistant lines, especially on $37-2$, was appreciably delayed. Nevertheless, for all the resistant lines, except Hi40, the score of diseased plants 50 dpi reached a maximum value $(A)$ close to that of the susceptible check B73. It is noteworthy that all plants of these resistant lines survived throughout the experiment despite being completely chlorotic, whereas $50 \%$ of the B73 plants were dead.

Effect of the number of insects on MStV resistance. Because ANOVA on the Gompertz parameters showed a significant effect of both IAP and trial on resistance to $\mathrm{MStV}$, we examined the assumption that this resistance is quantitative and, therefore, may vary in relation to cumulative number of inoculative planthoppers $\times$ hours (cnpih). We selected trials 2000-A, 1999-C, and 1998-C as representing, respectively, a low, an intermediate, and a very high cniph average effect on resistance to MStV. For data obtained at 42 dpi and for AUDPC, ANOVA at each IAP within each trial indicated a significant effect of genotype on disease incidence $(0.0001 \leq P \leq 0.003)$ and severity $(0.0001 \leq P \leq 0.013)$. A significant cage effect on incidence was found for 96-h IAP in trial 2000-A and 6-h IAP in trial 1999-C. In contrast, no cage effect was observed on severity, regardless of trial or IAP.

TABLE 3. Parameter estimates of Gompertz curves fitted to the Maize mosaic virus incidence and severity for five inbred lines

\begin{tabular}{llccc}
\hline & & \multicolumn{3}{c}{ Gompertz curves parameters $^{\mathrm{z}}$} \\
\cline { 3 - 5 } & Line & $A$ & $B$ & $C$ \\
\hline Incidence & $37-2$ & $44.9(8.1) \mathrm{c}$ & $0.292(0.030) \mathrm{c}$ & $12.32(0.82) \mathrm{a}$ \\
& $\mathrm{A} 211$ & $57.5(7.6) \mathrm{b}$ & $0.279(0.026) \mathrm{c}$ & $10.80(0.82) \mathrm{b}$ \\
& $\mathrm{B} 73$ & $77.3(5.7) \mathrm{a}$ & $0.505(0.038) \mathrm{a}$ & $6.10(0.44) \mathrm{d}$ \\
& Mp705 & $59.9(7.2) \mathrm{b}$ & $0.396(0.033) \mathrm{b}$ & $10.26(0.60) \mathrm{bc}$ \\
& Rev81 & $61.5(7.5) \mathrm{b}$ & $0.389(0.048) \mathrm{b}$ & $9.29(0.67) \mathrm{c}$ \\
Severity & $37-2$ & $9.05(0.22) \mathrm{a}$ & $0.131(0.018) \mathrm{b}$ & $25.86(3.00) \mathrm{a}$ \\
& A211 & $9.11(0.16) \mathrm{a}$ & $0.145(0.020) \mathrm{b}$ & $22.20(1.66) \mathrm{b}$ \\
& B73 & $9.44(0.08) \mathrm{a}$ & $0.218(0.028) \mathrm{a}$ & $12.96(1.14) \mathrm{d}$ \\
& Mp705 & $9.14(0.24) \mathrm{a}$ & $0.162(0.023) \mathrm{b}$ & $18.60(1.50) \mathrm{c}$ \\
& Rev81 & $9.06(0.14) \mathrm{a}$ & $0.142(0.018) \mathrm{b}$ & $19.86(2.01) \mathrm{c}$ \\
\hline
\end{tabular}

${ }^{\mathrm{z}}$ Numbers indicate the maximum percentage of plants presenting visible symptoms, for incidence, and the maximum mean score of plants presenting symptoms, for severity. Results are the means of five experiments (standard error). $A=$ upper asymptote, $B=$ slope parameter, and $C=$ point of inflexion. Values followed by the same letters are not significantly different at the 0.05 level according to Ryan-Einot-Gabriel-Welsh multiple range tests (REGW $Q$ test).

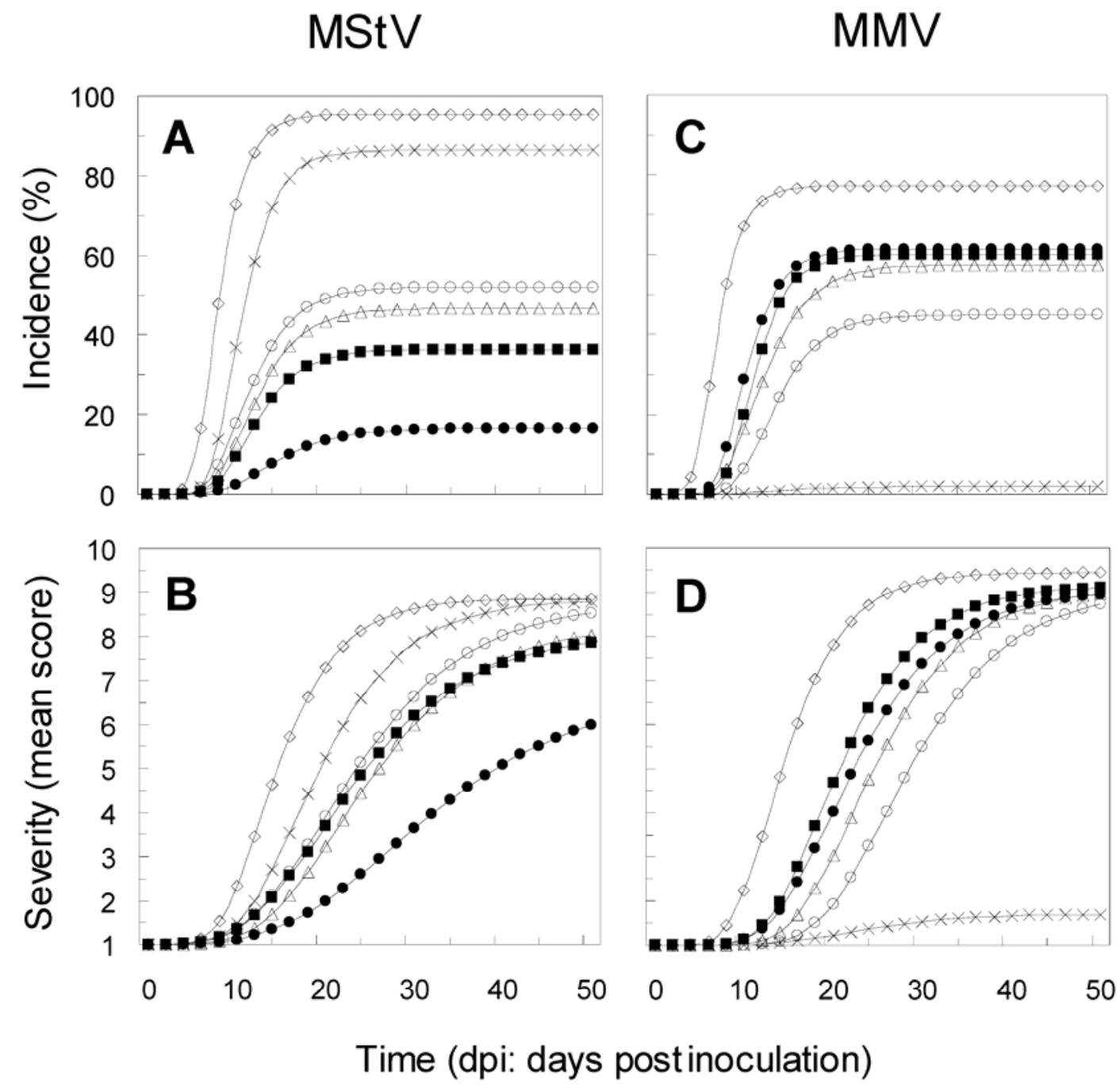

Fig. 1. Estimated disease $\mathbf{A}$ and $\mathbf{C}$, incidence and $\mathbf{B}$ and $\mathbf{D}$, severity due to Maize stripe virus (MStV) and Maize mosaic virus (MMV). Inbred lines tested were B73 $(\diamond)$, Hi40 $(\times), 37-2(\bigcirc)$, A211 $(\Delta)$, Mp705 (⿴), and Rev81 $(\bullet)$. Gompertz curves were plotted using mean values of Gompertz parameters from repeated experiments from 1998 to 2000. Adjusted $R^{2}$ values for the different lines ranged from 0.94 and 1.00 for MStV and 0.90 and 1.00 for MMV. It should be noted that the points plotted with the Gompertz model (the line) are neither predicted data nor actual data; they are marks to distinguish the different maize lines tested. 
Disease incidence increased according to cniph, but to a lesser degree when cniph was greater than 1,500 (Fig. 2A, C, and E). For the susceptible check B73, maximum MStV incidence was reached from cniph $\approx 1,000$, whereas for the susceptible line Hi40, disease progress was still slowly increasing to very high cniph values. Under very low inoculation pressure $($ cniph $<100)$ (Fig. 2A), lines 37-2, A211, and Mp705 were not distinguishable from resistant line Rev81. Under intermediate inoculation pressure (cniph $=500$ to 1,000$)$ (Fig. 2C), these lines ranged between Rev81 and B73, with Mp705 appearing more resistant than A211 and 37-2. Under very heavy inoculation pressure (cniph $>4,000$ ) (Fig. 2E), 37-2, A211, and Mp705 tended to behave in a manner similar to that of B73, whereas Rev81 stabilized at a low incidence value. At $42 \mathrm{dpi}$, following very heavy inoculation pressure (trial MStV 1998-C, 96-h IAP), these lines exhibited mean incidence values ranging from 90 to $100 \%$, whereas Rev81 never exceeded $36 \%$ (data not shown). So, the behavior of 37-2, A211, and Mp705 varied from highly resistant to completely susceptible when cniph increased, suggesting a quantitatively inherited resistance to MStV in these lines. In contrast, Rev81 did not exceed a low value of incidence, suggesting a strong resistance to MStV.

Disease severity also increased according to cniph, but rapidly stabilized for all lines from cniph $\approx 1,200$ to 1,500 (Fig. 2B, D, and F). Under low or intermediate inoculation pressure (Fig. 2B and D), all the lines appeared distinct from each other. As cniph increased, disease severity in lines 37-2, A211, and Mp705 was similar to B73 and Hi40, although Rev81 stabilized at a disease severity two times lower than the other lines, with plants showing moderate symptoms (Fig. 2F).

Effect of the number of insects on MMV resistance. As for $\mathrm{MStV}$, we tested the quantitative expression of MMV resistance when cniph increased, with trials 2000-A, 1999-C, and 1998-C representing a low, an intermediate, and a strong cniph average effect on resistance to MMV, respectively. For data obtained at $42 \mathrm{dpi}$ and for AUDPC, ANOVA at each IAP within each trial indicated a significant effect of genotype on disease incidence $(0.0001 \leq P \leq 0.03)$ and severity $(0.0001 \leq P \leq 0.0049)$. As for temporal analysis, Hi40 was discarded from this ANOVA in an effort to describe, more accurately, differences among the partially resistant lines. A significant cage effect on incidence was often observed, particularly for 6- and 24-h IAP, while more rarely on severity.

Disease incidence increased according to cniph, but to a lesser degree as soon as cniph reached values of $>200$ (Fig. 3A, C, and E). Maximum disease incidence in B73 was obtained under relatively low inoculation pressure ( cniph $=200$ to 300). In contrast, Hi40 behaved as a completely resistant line, even if some mild symptoms were sometimes observed on a few plants under heavy inoculation pressure (Fig. 3E). Small but significant differences were observed for incidence among lines 37-2, A211, Mp705, and

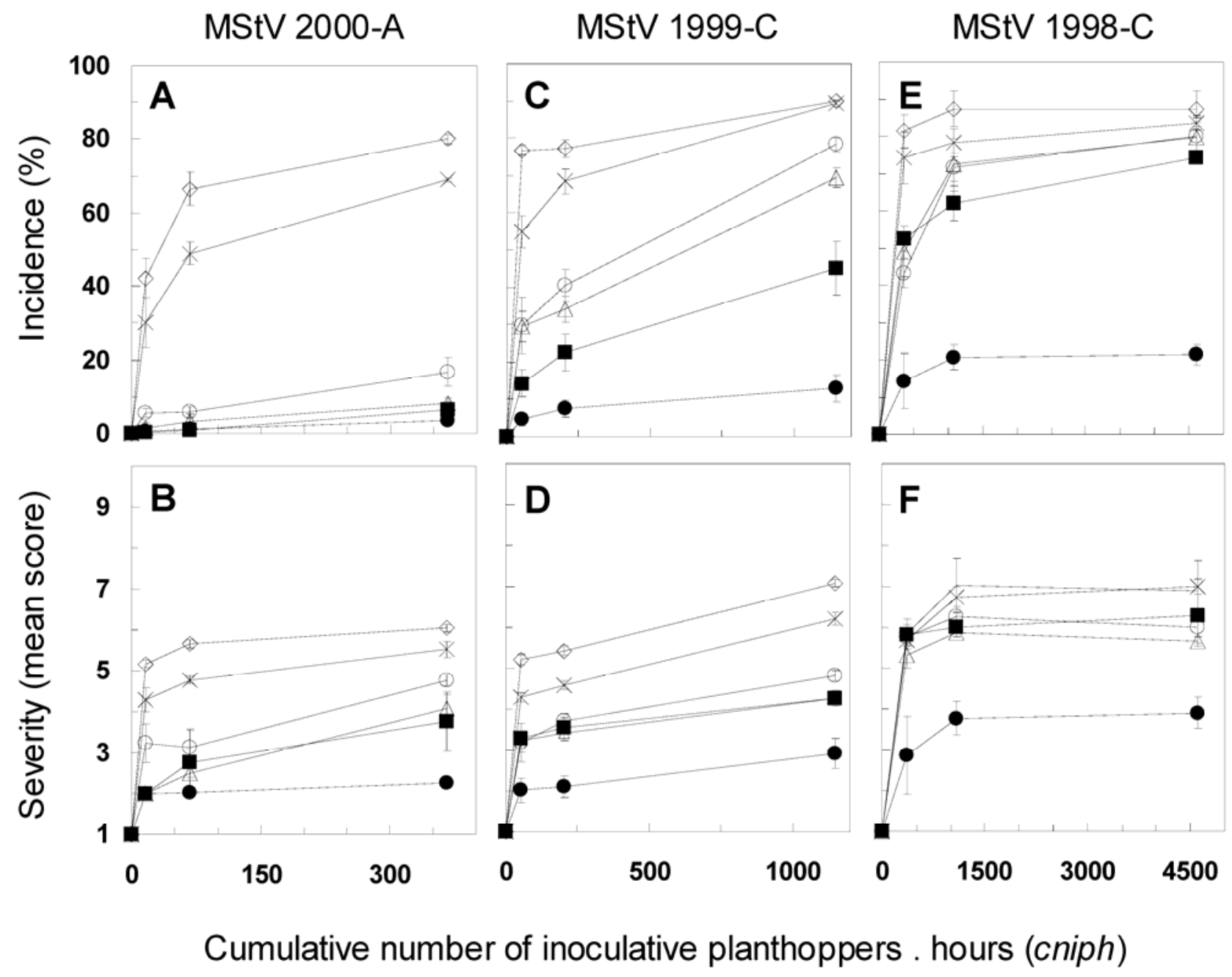

Fig. 2. Disease $\mathbf{A}, \mathbf{C}$, and $\mathbf{E}$, incidence and $\mathbf{B}, \mathbf{D}$, and $\mathbf{F}$, severity of Maize stripe virus (MStV) versus the cumulative number of inoculative planthoppers $\times$ hours

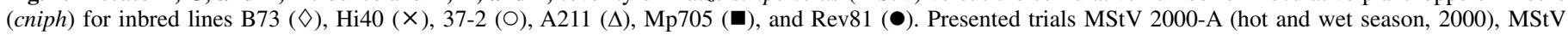
1999-C (hot and dry season, 1999), and MStV 1998-C (hot and dry season, 1998) were characterized by low inoculation pressure, intermediate inoculation pressure, and very strong inoculation pressure, respectively. In each trial, the MStV incidence and severity are represented by the area under disease progress curve means over all cages, with bars as the standard errors. The cniph values in each trial are the means over all cages for each inoculation access period (Table 1). 
Rev81. Line 37-2 showed the highest partial resistance and was slightly separated from the group of lines A211, Mp705, and Rev81, which did not differ from each other.

Disease severity progress according to cniph in lines 37-2, A211, Mp705, and Rev81 appeared to be relatively close to that of B73 (Fig. 3D and F). Nevertheless, some differences were observed among genotypes for severity, especially under low inoculation pressure (Fig. 3B). At $42 \mathrm{dpi}$, following a heavy inoculation pressure (trial MMV 1998-C, 96-h IAP), $100 \%$ of the plants in these four lines were severely diseased, with a symptom rating of 9, almost equivalent to that observed on B73 (data not shown).

\section{DISCUSSION}

The transmission efficiency of mass-reared planthoppers was found to be much higher for MStV than for MMV, in accordance with previous studies on transmission of these viruses by $P$. maidis populations from Réunion Island (26). Inoculative insects were easier to obtain for MStV than for MMV, because MStV may be acquired by feeding on infected plants as well as by transovarial transmission to the progeny. This probably explained most of the differences in cniph between the MStV and MMV trials. However, despite the lower efficiency of MMV transmission, enough viruliferous insects were produced to test our lines under severe inoculation pressure with this virus.

Our study demonstrates that different levels of resistance to propagative viruses transmitted by $P$. maidis can be found in maize germ plasm from Mascarene and the Caribbean. Although tolerance to MStV was previously identified in maize lines from Venezuela and Australia $(11,15)$, and partial resistance was reported in a population from Réunion (12), to our knowledge, this is the first report of MStV resistance evaluated under artificial inoculations with increasing numbers of inoculative $P$. maidis. Genotype Rev81 exhibited a strong resistance to MStV, with less than $20 \%$ of the plants being infected, on average, over all experiments. Temporal analyses of disease progression indicated that resistance in Rev81 had a greater effect on disease incidence than on severity. Nevertheless, significant differences in disease severity progress curves between Rev81 and the susceptible check B73 suggested that resistance factors in Rev81 both delayed and reduced the development of MStV symptoms on leaves. This resistance was not overcome by heavy inoculation pressure. The experiment with the most intense inoculation pressure, about 60 inoculative insects per single Rev81 plant in a 96-h IAP, failed to produce more than $40 \%$ infection with $\mathrm{MStV}$. In other respects, a moderate level of resistance to $\mathrm{MStV}$ was found in genotypes Mp705, A211, and 37-2. This resistance was characterized by a

\section{2000-A}
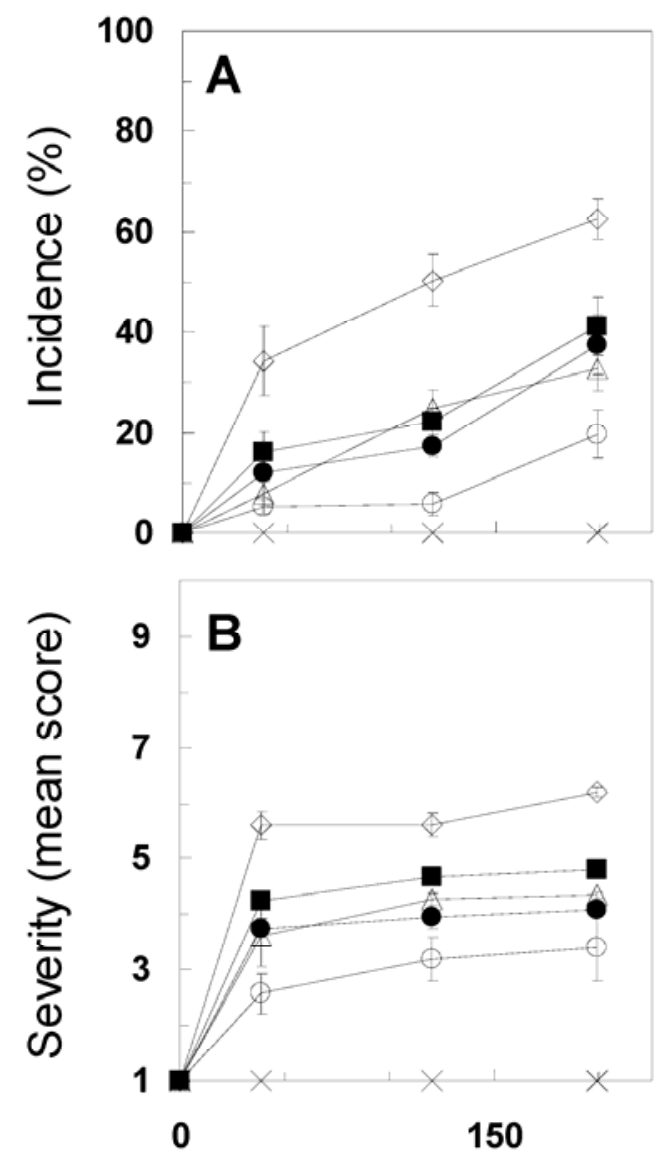

\section{Cumulative number of inoculative planthoppers . hours (cniph)}

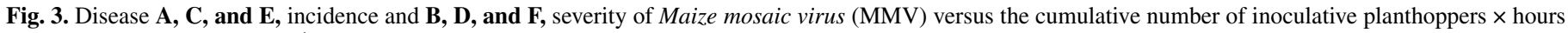

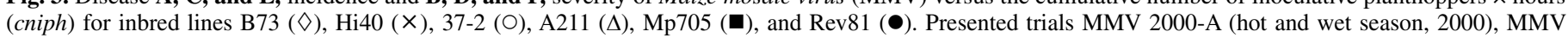

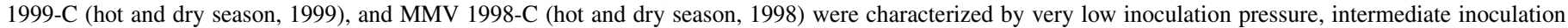

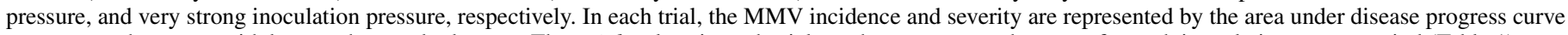
means over the cages, with bars as the standard errors. The cniph values in each trial are the means over the cages for each inoculation access period (Table 1). 
disease incidence between 50 and $60 \%$ lower than that in susceptible check B73 and a 3- to 4-day delay in symptom appearance. Symptoms on infected plants continued to develop until they resembled those on B73, after a delay of approximately 2 weeks. Disease progression in relation to cumulative number of planthoppers showed that this partial resistance typically was expressed as a quantitative trait and could be completely overcome by an intense inoculation pressure of more than 15 inoculative planthoppers feeding on a single plant for $96 \mathrm{~h}$. These results highlight the distinction between highly resistant Rev81 and partially resistant lines Mp705, A211, and 37-2, which are not effective against $\mathrm{MStV}$ at high inoculation pressure.

In a previous gene-mapping study, the near complete resistance to MMV observed in line Hi31 as well as in Hi40 was demonstrated to be a highly heritable trait based on a single major gene $(20,25)$. Since Hi40 reacted to MStV in a manner almost identical to that of the susceptible control B73, this gene can be considered MMV-specific without any significant effect on MStV. In line 37-2, and to a lesser extent in A211, Rev81, and Mp705, we also identified partial resistance to MMV. This partial resistance to MMV was expressed as a quantitative trait and was overcome by a moderate inoculation pressure corresponding to about five inoculative insects feeding on a single plant for $96 \mathrm{~h}$.

It is noteworthy that lines 37-2, A211, Rev81, and Mp705 showed resistance to both MStV and MMV. This could mean that factors of resistance to each virus are present in these genotypes, or that some factors of resistance are efficient against the two viruses at the same time. Because resistance in these lines mainly reduced the incidence component of the disease, factors of resistance against both viruses could be preferentially involved at an early stage of the replication cycle of the virus in the plant or at the level of vector transmission. Given the available data, it is not possible to distinguish among these two hypotheses. Nevertheless, genetic factors affecting virus transmission are consistent with previous studies on the feeding behavior of $P$. maidis (4). Thus, electrical penetration graphs analyses, carried out on the same six lines tested herein, showed that the feeding behavior of $P$. maidis was significantly disturbed in line $37-2$, and in a lesser degree in lines Mp705, A211, and Rev81 when compared with $\mathrm{Hi} 40$ and B73, this last one being the susceptible check. We demonstrated that the factors, which explained resistance-susceptibility status of the maize lines, were mainly related to total time the insect takes for passive ingestion in phloem tissues as well as for stylet activity to reach these tissues (unpublished data). Because viruses transmitted by $P$. maidis likely are deposited within phloem through watery salivation, altered feeding behavior could result in significant restriction of virus spread and contribute to the decreased incidence of virus infection observed in these lines. This type of resistance to the vector has been observed in studies with other virus-vector-host systems, especially with Rice ragged stunt virus transmitted by planthopper Nilaparvata lugens (Stål) (Homoptera: Delphacidae) on rice (24). It would by interesting to know how resistance to transmission in Mp705 may be tied back to previously identified resistance to Lepidoptera in this line (29). Although we cannot exclude the presence in Mp705 of genes controlling mechanisms of defense that are effective against both lepidopteran and homopteran, this hypothesis is yet unlikely insofar because most of the mechanisms involved are probably different for piercing-sucking insects and leaf-feeders.

The reaction of Rev81, Mp705, A211, and 37-2 to MStV and MMV, especially for disease incidence, suggests polygenic control of resistance to these viruses. This hypothesis is consistent with other studies of quantitative resistance to viruses that are often characterized by reduced disease incidence. In this rate-reducing type of resistance, all plants can be infected, but the chance of infection is reduced as shown, for example, in groundnut resistant to peanut bud necrosis disease (5). For MStV, the most effective combination of resistance genes should be present in the highly resistant line Rev81, probably involving major quantitative trait loci (QTL) of resistance to this virus. Further studies are needed to dissect these factors and to distinguish resistance to virus sensu stricto from resistance to $P$. maidis. Thus, QTL mapping with examination of virus resistance under mechanical inoculation parallel to vector transmission could clarify different genetic factors that may be involved. For the moment, classical methods of mechanical transmission (rub or pin inoculation) are not adequate for either MStV or MMV $(16,17)$.

In this study, Rev81 showed the highest level of resistance to $\mathrm{MStV}$ ever reported and proved to be effective by significantly reducing disease incidence and by moderately reducing symptom severity. We confirmed highly specific resistance to MMV in Hi40. Quantitative resistance detected in lines Mp705, A211, and 37-2 may involve virus resistance as well as vector resistance. As shown in studies on other crops (14), a virus nonspecific resistance to $P$. maidis could significantly reduce the impact of both MStV and MMV under natural planthopper infection. Accordingly, nonspecific and specific resistance to MStV and MMV could be combined to confer a higher and more durable resistance against the $P$. maidis-MStV-MMV complex. Although none of our lines are agronomically desirable, they are promising donors of resistance for use in maize breeding programs.

\section{ACKNOWLEDGMENTS}

This work was funded by CIRAD and by la Région Réunion. We thank B. Courtois (CIRAD, Montpellier, France). We thank D. Verger (SERASEM, La Brosse Montceaux, France), R. P. Hoareau, and M. Grondin (CIRAD, Saint-Pierre, Réunion Island) for technical assistance.

\section{LITERATURE CITED}

1. Ammar, E. D., Gingery, R. E., and Madden, L. V. 1995. Transmission efficiency of three isolates of maize stripe tenuivirus in relation to virus titre in the planthopper vector. Plant Pathol. 44:239-243.

2. Autrey, L. J. C. 1980. Studies on maize mosaic virus, its strains and economic importance. Ph.D. thesis. University of Exeter, England.

3. Brewbaker, J. L. 1979. Diseases of maize in the wet lowland tropics and the collapse of the classic Maya civilization. Econ. Bot. 33:101118.

4. Buduca, C. 1995. Etude du comportement alimentaire de Peregrinus maidis (Ashmead, 1890) (Homoptera) par électropénétrographie, en relation avec la résistance à la mosaïque du maïs. $\mathrm{Ph} . \mathrm{D}$. thesis. Université des Sciences et Techniques du Languedoc, Montpellier, France.

5. Buiel, A. A. M., and Parlevliet, J. E. 1995. Epidemiology of peanut bud necrosis disease in groundnut in India. Recent studies on peanut bud necrosis disease: Proceedings of a meeting on 20 March 1995. A. A. M. Buiel, J. E. Parlevliet, and J. M. Lenné, eds. ICRISAT, Asia Center, India.

6. Campbell, C. L., and Madden, L. V. 1990. Models for analyzing disease progress. Pages 167-192 in: Introduction to Plant Disease Epidemiology. John Wiley \& Sons, New York.

7. Clerget, B., Dintinger, J., and Reynaud, B. 1996. Registration of maize inbred CIRAD390 parental line. Crop Sci. 36:826.

8. Delpuech, I., Bonfils, J., and Leclant, F. 1986. Contribution à l'étude des virus du maïs transmis par homoptères auchenorrhynques à l'île de la Réunion. Agronomie 6:549-554.

9. Etienne, J., and Rat, B. 1973. Le Stripe: Une maladie importante du maïs à la Réunion. Agron. Trop. 28:11-17.

10. Falk, B. W., and Tsai, J. H. 1985. Serological detection and evidence for multiplication of maize mosaic virus in the planthopper, Peregrinus maidis. Phytopathology 75:852-855.

11. Greber, R. S. 1981. Maize stripe disease in Australia. Aust. J. Agric. Res. 32:27-36.

12. Hainzelin, E., and Marchand, J. L. 1986. Registration of IRAT297 maize germplasm. Crop Sci. 26:1090-1091.

13. Jeger, M. J., and Viljanen-Robinson, S. 2001. The use of area under the disease progress curve (AUDPC) to assess quantitative disease resistance in crop cultivars. Theor. Appl. Genet. 102:32-40.

14. Jones, A. T. 1987. Control of virus infection in crop plants through vector resistance: A review of achievements, prospects and problems. Ann. Appl. Biol. 111:745-772.

15. Lastra, R. J., and Carballo, O. 1983. Maize virus diseases problems in Venezuela. Pages 83-86 in: Proc. Int. Maize Virus Dis. Colloq. Workshop. 
D. T. Gordon, J. K. Knoke, L. R. Nault, and E. Ritter, eds. Ohio State Univ. Agric. Res. Develop. Center, Wooster.

16. Lastra, R. J., and Carballo, O. 1985. Mechanical transmission, purification and properties of maize stripe virus from Venezuela. Phytopathol. Z. 114:168-179.

17. Louie, R. 1995. Vascular puncture of maize kernels for the mechanical transmission of maize white line mosaic virus and other viruses of maize. Phytopathology 85:139-143.

18. Marchand, J. L., Peterschmitt, M., and Reynaud, B. 1994. Maize streak virus, maize stripe virus and maize mosaic virus in the tropics (Africa and islands of the Indian Ocean). Agric. Dévelop. 4:1-16.

19. Migliori, A., and Lastra, R. J. 1980. Etude d'une maladie de type viral présente sur maïs en Guadeloupe et transmise par le delphacide Peregrinus maidis. Ann. Phytopathol. 12:277-294.

20. Ming, R., Brewbaker, J. L., Pratt, R. C., Musket, T. A., and McMullen, M. D. 1997. Molecular mapping of a major gene conferring resistance to maize mosaic virus. Theor. Appl. Genet. 95:271-275.

21. Nault, L. R., and Ammar, E. D. 1989. Leafhopper and planthopper transmission of plant viruses. Annu. Rev. Entomol. 34:503-529.

22. Nault, L. R., and Gordon, D. T. 1988. Multiplication of maize stripe virus in Peregrinus maidis. Phytopathology 78:991-995.

23. Nault, L. R., Gordon, D. T., Gingery, R. E., Bradfute, O. E., and Castillo
Loayza, J. 1979. Identification of maize viruses and mollicutes and their potential insects vectors in Peru. Phytopathology 69:824-828.

24. Parejarearn, A., Lapis, D. B., and Hibino, H. 1984. Reaction of rice varieties to rice ragged stunt virus (RSV) infection by three brown planthopper (BPH) biotypes. Int. Rice Res. News1. 9:7-8.

25. Pernet, A. 1998. Cartographie génétique des facteurs de résistance du maïs aux virus tropicaux de la striure et de la mosaïque. Ph.D. thesis. Université Paris XI, Orsay, France.

26. Reynaud, B. 1988. Transmission des virus de la striure, du stripe et de la mosaïque du maïs par leurs vecteurs Cicadulina mbila (Naude, 1924) et Peregrinus maidis (Ashmead, 1890) (Homoptera). Approaches biologique, génétique et épidémiologique de la relation vecteur-virus-plante. Ph.D. thesis. Université des Sciences et Techniques du Languedoc, Montpellier, France.

27. Rodier, A., Assié, J., Marchand, J. L., and Hervé, Y. 1995. Breeding maize lines for complete and partial resistance to maize streak virus (MSV). Euphytica 81:57-70.

28. Thottappilly, G., Bosque-Pérez, N. A., and Rossel, H. W. 1993. Viruses and virus diseases of maize in tropical Africa. Plant Pathol. 42:494-509.

29. Williams, W. P., and Davis, F. M. 1984. Registration of Mp705, Mp706, and Mp707 germplasm lines of maize. Crop Sci. 24:1217. 